\title{
Retraction Note to: The effect of the electronic structure, phase transition, and localized dynamics of atoms in the formation of tiny particles of gold
}

\author{
Mubarak Ali • I-Nan Lin
}

Published online: 5 September 2017

C) Springer Science+Business Media B.V. 2017

Retraction Note to: J Nanopart Res (2017) 19: 15

DOI 10.1007/s11051-016-3710-9

This article has been retracted at the request of the authors and the Editor-in-Chief, who noted an administrative error. The Editor in Chief accidentally accepted while the editorial recommendation was meant to be a rejection. The journal apologizes for this error.

The online version of the original article can be found at http://dx. doi.org/10.1007/s11051-016-3710-9

M. Ali $(\bowtie)$

Department of Physics, COMSATS Institute of Information, Technology, Islamabad 45550, Pakistan

e-mail: mubarak74@ comsats.edu.pk

e-mail: mubarak74@mail.com

I.-N. Lin

Department of Physics, Tamkang University, Tamsui Dist, New

Taipei City, 25137 Taiwan, Republic of China 